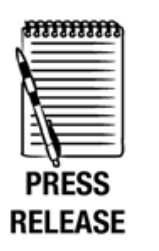

Academic Unit of Medicines Management, School of Healthcare, Baines Wing, University of Leeds, Leeds, UK

${ }^{2}$ Medical Statistics Unit, London School of Hygiene and Tropical Medicine, London, UK

${ }^{3}$ The School of Pharmacy, BMA House, Tavistock Square, University of London, London, UK

Correspondence to Dr David Phillip Alldred, Academic Unit of Medicines Management, School of Healthcare, Baines Wing, University of Leeds, Leeds LS2 9UT, UK;

d.p.alldred@leeds.ac.uk

Accepted 3 December 2010 Published Online First 7 February 2011

\title{
The influence of formulation and medicine delivery system on medication administration errors in care homes for older people
}

\author{
David Phillip Alldred, ${ }^{1}$ Claire Standage, ${ }^{1}$ Olivia Fletcher, ${ }^{2}$ Imogen Savage, ${ }^{3}$ \\ James Carpenter, ${ }^{2}$ Nick Barber, ${ }^{3}$ David Kenneth Raynor ${ }^{1}$
}

\section{ABSTRACT}

Introduction: Older people in care homes are at increased risk of medication errors and adverse drug events. The effect of formulation on administration errors is not known, that is whether the medicine is a tablet or capsule, liquid or device such as an inhaler. Also, the impact on administration errors of monitored dosage systems (MDS), commonly used in UK care homes to dispense tablets and capsules, is not known. This study investigated the influence of formulation and MDS on administration errors.

Methods: Administration errors were identified by pharmacists (using validated definitions) observing two drug rounds of residents randomly selected from a purposive sample of UK nursing and residential homes. Errors were classified and analysed by formulation and medicine delivery system.

Results: The odds of administration errors by formulation, when compared with tablets and capsules in MDS, were: liquids 4.31 ( $95 \% \mathrm{Cl} 2.02$ to 9.21; $p=0.0002)$; topicals/transdermals/injections 19.61 (95\% Cl 6.90 to $55.73 ; \mathrm{p}<0.0001$ ); inhalers $33.58(95 \% \mathrm{Cl} 12.51$ to $90.19 ; \mathrm{p}<0.0001)$. The odds of administration errors for tablets and capsules not in MDS were double those that were dispensed in MDS (adjusted OR 2.14, 95\% Cl 1.02 to $4.51 ; p=0.04$ ).

Conclusions: Inhalers and liquid medicines were associated with significantly increased odds of administration errors. Training of staff in safe administration of these formulations needs implementing. Although there was some evidence that MDS reduced the odds of an administration error, the use of MDS impacts on other aspects of medicines management. Because of this, and as the primary topic of our study was not MDS, a prospective trial specifically designed to evaluate the overall impact of MDS on medicine management in care homes is needed.

\section{INTRODUCTION}

Older people living in care homes (long-term care facilities) are at a high risk of medication errors and subsequent adverse events. Reasons for this include polypharmacy, comorbidities, altered pharmacokinetics and pharmacodynamics, and the complex medicines management system used in care homes. $^{1-5}$ Errors can occur during the prescribing, monitoring and dispensing of medicines or during administration on the drug round. In the Care Homes' Use of Medicine Study, administration errors occurred in $22.3 \%$ of residents and $8.4 \%$ of observed medication administration events. ${ }^{6}$

Tablets and capsules are usually packaged into monitored dosage systems (MDS; termed unit dose systems in some countries) for care homes in the UK, with $86 \%$ of care homes using MDS. ${ }^{6}$ MDS comprise a rectangular tray or cassette with compartments for one or more doses for a particular day and time (ie, breakfast, lunch, dinner, bedtime).

Alternatively, medicines may be dispensed in original manufacturers' packaging (nonMDS). Many formulations and preparations cannot be packaged into MDS-for example, effervescent, buccal and sublingual tablets, cytotoxics, liquids, hygroscopic formulations, inhalers, refrigerator items and injections. ${ }^{7}$ Therefore, for each resident, there are usually at least two medicine delivery systems operating in parallel, that is medicines in MDS and medicines in original packaging.

MDS are intended to simplify the administration process for staff; instead of selecting tablets from an individual medicine bottle or box, after checking the medicine administration record, the carer only needs to verify 
the identity of the resident and administer the tablets from the compartment that relates to the date and time.

Despite widespread use of MDS, there is a paucity of robust evidence to conclude they are a safer system of administration than the manufacturer's original packaging. Two before and after studies in the mid-1980s (one in the USA, one in the UK), conducted in single long-term care facilities, reported a reduction in medication administration errors following the introduction of MDS. ${ }^{8} 9$

We found no significant difference in administration error rates when comparing care home residents' principal medicines delivery system (ie, MDS or non-MDS). ${ }^{6}$ However, when individual medication administration errors were analysed, there was an increased odds of error in non-MDS versus MDS (OR 3.16 95\% CI 1.43 to 6.95) ${ }^{6}$ Critically, this analysis did not compare like with like because a proportion of the non-MDS errors involved medicines that were not tablets or capsules, for example inhalers, which have a greater potential for being administered incorrectly.

In addition, our original analysis did not investigate differences in medication administration error rates involving tablets and capsules compared with other formulations.

The objectives of this study were therefore to:

1. Determine if there were any differences in administration error rates between tablets and capsules and other formulations;

2. Determine if there were any differences in medication administration error rates between tablets and capsules dispensed in MDS and those dispensed in the manufacturer's original packaging.

\section{METHOD}

\section{Participants}

Fifty-five UK care homes were purposively sampled to obtain a diverse sample based on ownership, size and type of care provided (nursing, residential or both), and residents prescribed one or more medicines were randomly sampled and included if they provided written, informed consent (assent was obtained from the next of kin for those lacking capacity) ${ }^{6}$

\section{Data collection}

Data were extracted from the paper-based, administration error observation forms from our previous study. ${ }^{6}$ Medication administration errors were identified by clinical pharmacists observing two drug rounds per resident as defined using previous work by Allan and Barker ${ }^{10}$ and Dean and Barber ${ }^{11}$ as 'any deviation between the medication prescribed and that administered.' The number of opportunities for error (denominator) was the number of doses observed being given, plus any doses that should have been given but were omitted.

Medication administration errors were classified into five categories according to medicine delivery system and formulation:

- Tablets/capsules in MDS;

- Tablets/capsules not in MDS;

- Liquids;

- Inhalers;

- A combined group of topical, transdermal and injectable formulations.

We hypothesised that the administration error rates may differ depending on whether medicines were prescribed regularly or when required; therefore, medicines were classified accordingly. Data were recorded for each home relating to the UK care home regulator's (Care Quality Commission (CQC)) rating at the time of the research, according to National Minimum Standard 9 pertaining to Medicines 'Service users... are protected by the home's policies and procedures for dealing with medicines.' Scores are allocated by the CQC as follows:

1. Standard not met (major shortfalls);

2. Standard almost met (minor shortfalls);

3. Standard met (no shortfalls);

4. Standard exceeded (commendable).

This was conducted because we postulated that homes with lower CQC ratings may have higher administration error rates. Analysis from our previous study ${ }^{6}$ found that increasing resident age and residential care (vs nursing care) were associated with more administration errors, and therefore the age of residents and type of care were recorded.

\section{Data analysis}

Statistical analyses were performed using STATA version 10. Summary statistics (proportions and means) were calculated with reference to the number of homes participating in the study, the number of residents participating in the study and the total number of medicines that should have been administered to residents (opportunities for error as defined above). Unadjusted and adjusted ORs for each category of medicine delivery system were calculated using unconditional logistic regression with tablets/capsules in MDS as the baseline group. The clustered design of the study was taken into account by the use of robust standard errors for estimating 95\% CIs and $p$ values. All statistical tests are two-sided.

\section{RESULTS}

Individual data on formulation, medicine delivery system and administration errors were available for 233 residents in 55 care homes. Table 1 shows demographic 


\begin{tabular}{|c|c|c|c|}
\hline & $\begin{array}{l}\text { Homes } \\
\mathrm{N}=55\end{array}$ & $\begin{array}{l}\text { Individuals } \\
N=233\end{array}$ & $\begin{array}{l}\text { Medicines } \\
N=1380\end{array}$ \\
\hline \multicolumn{4}{|l|}{ Type of care } \\
\hline Residential & $30(54.6)$ & $124(53.2)$ & $742(53.8)$ \\
\hline Nursing & $25(45.4)$ & $109(46.8)$ & $638(46.2)$ \\
\hline \multicolumn{4}{|l|}{ Age at review } \\
\hline$<80$ & & $61(26.2)$ & $395(28.6)$ \\
\hline $80-89$ & & 93 (39.9) & $551(39.9)$ \\
\hline $90+$ & & 79 (33.9) & $434(31.4)$ \\
\hline \multicolumn{4}{|l|}{ Care Quality Commission standard 9 rating* } \\
\hline 1 & $3(5.6)$ & $15(6.6)$ & $70(5.1)$ \\
\hline 2 & $15(27.8)$ & $61(26.6)$ & $347(25.5)$ \\
\hline 3 & $36(66.7)$ & $153(66.8)$ & $944(69.4)$ \\
\hline \multicolumn{4}{|l|}{ Type of delivery system } \\
\hline Monitored dosage system tablets/capsules & & & $732(53.0)$ \\
\hline Non-monitored dosage system tablets/capsules & & & $404(29.3)$ \\
\hline Liquids & & & $164(11.9)$ \\
\hline Inhalers & & & $52(3.8)$ \\
\hline Topicals & & & $26(1.9)$ \\
\hline Transdermals & & & $1(0.1)$ \\
\hline Injections & & & $1(0.1)$ \\
\hline \multicolumn{4}{|l|}{ Regular or when required medicines } \\
\hline Regular & & & $1275(92.4)$ \\
\hline When required & & & $105(7.6)$ \\
\hline
\end{tabular}

data. Tablets and capsules in MDS accounted for 53.0\% of observed administrations, with the corresponding figures being: for tablets and capsules not in MDS, 29.3\%; liquids, $11.9 \%$; and inhalers $3.8 \%$. The remaining $2.1 \%$ of observed administrations were topical, transdermal or injectable formulations.

Table 2 details administration errors according to formulation and medicine delivery system. The mean number of errors per resident was similar for tablets and capsules in MDS (0.17); tablets and capsules not in MDS (0.20); and liquids (0.21). However, the mean number of errors per resident was higher for the combined category of topical/transdermal/injection (0.55) and inhalers (1.13).

The unadjusted OR (table 2) suggested that administration of tablets and capsules in their original packaging was associated with an approximately $70 \%$ higher risk of error compared with administration of tablets and capsules in MDS (1.00 vs 1.68), but this difference was not statistically significant $(p=0.15)$. However, when the analysis was adjusted for regular or when-required medicines, age group, type of care and CQC rating, there was a statistically significant doubling of the odds of an error for tablets and capsules not in MDS (OR $2.14,95 \%$ CI 1.02 to $4.51 \mathrm{p}=0.04)$.

The adjusted and unadjusted analyses of error rates were statistically significantly higher for liquids, topical/ transdermals/injections and inhalers, when compared with tablets and capsules in MDS, with adjusted analyses showing a fourfold increase in the odds of an error for liquids (4.31 95\% CI 2.02 to $9.21 \mathrm{p}=0.0002$ ), a 20-fold increase for topicals/transdermals/injections (19.61 $95 \%$ CI 6.90 to $55.73 \mathrm{p}<0.0001)$ and a 30 -fold increase in the odds of an error for inhalers $(33.5995 \%$ CI 12.51 to $90.19 \mathrm{p}<0.0001$ ) (figure 1). The CQC score was unavailable for one home with 19 observations for four residents. These data are excluded from the fully adjusted model.

\section{DISCUSSION}

It is unsurprising that inhalers have higher rates of administration errors than tablets and capsules, as they are complex devices requiring a number of steps to be correctly undertaken in the right sequence for successful administration. The main reasons why inhalers were administered erroneously in this study included: not shaking the device; the resident not holding their breath (usually with visible powder escaping the mouth); and the wrong number of inhalations being administered. Half of all inhaler administrations were incorrect, and this represents a highly significant loss of potential clinical benefit, which may reduce quality of life owing to untreated respiratory disease (and represent a significant waste of NHS money). Liquid formulations are commonly prescribed in this setting owing to dysphagia, and the risk of administration errors with liquids was four times higher than tablets and 
Table 2 Medication administration errors according to medicine delivery system and formulation

\begin{tabular}{|c|c|c|c|c|c|}
\hline & $\begin{array}{l}\text { Monitored dosage } \\
\text { system tablets/ } \\
\text { capsules } \\
N=180 \\
n=732\end{array}$ & $\begin{array}{l}\text { Non-monitored } \\
\text { dosage system } \\
\text { tablets/capsules } \\
N=138 \\
n=404\end{array}$ & $\begin{array}{l}\text { Liquids } \\
\mathrm{N}=96 \\
\mathrm{n}=164\end{array}$ & $\begin{array}{l}\text { Inhalers } \\
\mathrm{N}=23 \\
\mathrm{n}=\mathbf{5 2}\end{array}$ & $\begin{array}{l}\text { Topicals, } \\
\text { transdermals } \\
\text { and injections } \\
\mathrm{N}=20 \\
\mathrm{n}=28\end{array}$ \\
\hline \multicolumn{6}{|l|}{ Errors per resident } \\
\hline $0(\%)$ & $161(89.4)$ & $119(86.2)$ & $82(85.4)$ & $12(52.2)$ & $11(55.0)$ \\
\hline $1(\%)$ & $13(7.2)$ & $13(9.4)$ & $9(9.4)$ & $6(26.1)$ & $7(35.0)$ \\
\hline $2+(\%)$ & $6(3.3)$ & $6(4.3)$ & $5(5.2)$ & $5(21.7)$ & $2(10.0)$ \\
\hline Total (\%) & $19 / 180(10.6)$ & 19/138 (13.8) & $14 / 96(14.6)$ & $11 / 23(47.8)$ & $9 / 20(45.0)$ \\
\hline $\begin{array}{l}\text { Mean no of errors } \\
\text { per resident }\end{array}$ & 0.17 & 0.20 & 0.21 & 1.13 & 0.55 \\
\hline Mean no of errors & $31 / 732$ & $28 / 404$ & $20 / 164$ & $26 / 52$ & $11 / 28$ \\
\hline per medicine & 0.042 & 0.069 & 0.122 & 0.500 & 0.393 \\
\hline $\begin{array}{l}\text { OR for error } \\
(95 \% \mathrm{Cl}) \text { unadjusted }\end{array}$ & Ref (1.00) & $\begin{array}{l}1.68 \text { (0.83 to } \\
3.44) \\
p=0.15\end{array}$ & $\begin{array}{l}3.14(1.51 \text { to } \\
6.55) \\
p=0.002\end{array}$ & $\begin{array}{l}22.61 \text { (8.49 to } \\
60.24) \\
p<0.0001\end{array}$ & $\begin{array}{l}14.63 \text { (5.68 to } \\
37.71) \\
p<0.0001\end{array}$ \\
\hline $\begin{array}{l}\text { OR adjusted for } \\
\text { regular or when } \\
\text { required }(95 \% \mathrm{Cl})\end{array}$ & Ref (1.00) & $\begin{array}{l}1.50(0.73 \text { to } \\
3.11)\end{array}$ & $\begin{array}{l}3.09(1.48 \text { to } \\
6.44)\end{array}$ & $\begin{array}{l}20.20(7.58 \text { to } \\
53.84)\end{array}$ & $\begin{array}{l}13.89(5.17 \text { to } \\
37.31)\end{array}$ \\
\hline & & $\mathrm{p}=0.27$ & $p=0.003$ & $\mathrm{p}<0.0001$ & $\mathrm{p}<0.0001$ \\
\hline $\begin{array}{l}\text { OR }(95 \% \mathrm{Cl}) \\
\text { adjusted for regular or } \\
\text { when required, } \\
\text { age group, type } \\
\text { of care, Care Quality } \\
\text { Commission rating }\end{array}$ & Ref (1.00) & $\begin{array}{l}2.14(1.02 \text { to } \\
4.51) \\
p=0.04\end{array}$ & $\begin{array}{l}4.31(2.02 \text { to } \\
9.21) \\
p=0.0002\end{array}$ & $\begin{array}{l}33.59(12.51 \text { to } \\
90.19) \\
p<0.0001\end{array}$ & $\begin{array}{l}19.61 \text { (6.90 to } \\
55.73) \\
p<0.0001\end{array}$ \\
\hline
\end{tabular}

capsules. Other than omissions, errors were mainly due to inaccurately measuring the volume and not shaking the bottle of suspensions. Most of the topical administration errors were due to eye-drops that had expired or were omitted.

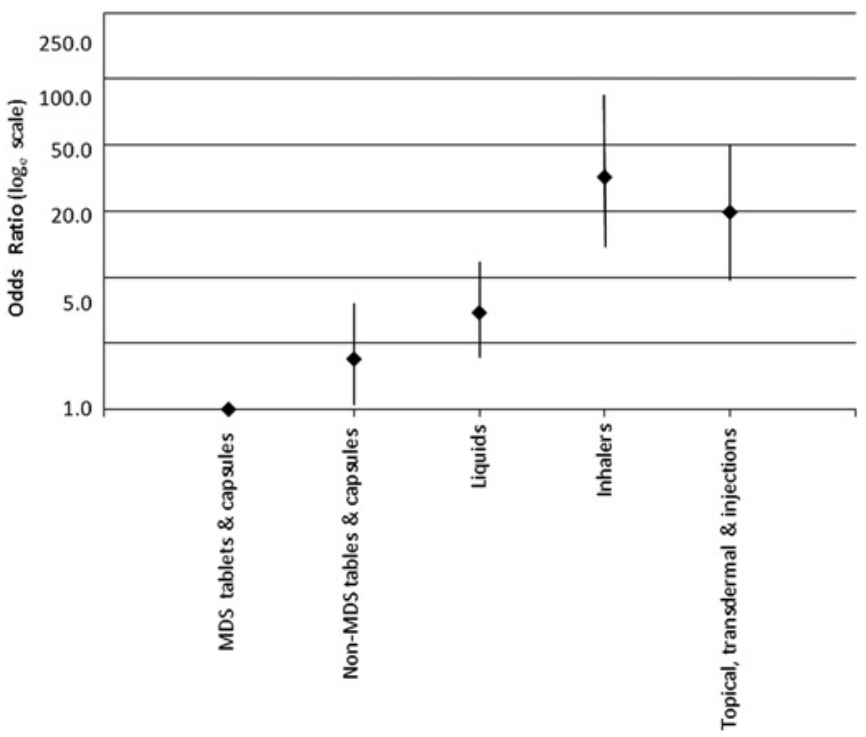

Figure 1 Adjusted odds ratios of administration errors according to formulation and medicine delivery system. MDS, monitored dosage system.
We found some evidence that MDS are safer, with approximately half the odds of administration errors when compared with tablets and capsules in the manufacturers' original packaging. The evidence for this observation, however, was of marginal significance $(\mathrm{p}=0.04)$, and any adjustment for multiple testing would have reduced the significance further. There was strong evidence that administration of medicines in liquid form, via inhalers and by topical, transdermal or injected form was associated with a higher risk of error, and these observations would remain robust after any adjustment for multiple testing.

There are a number of limitations to our study. First, our original study was not designed to assess differences in error rates between formulations and between medicine delivery systems. ${ }^{6}$ Second, the proportion of medicines that were administered as liquids, inhalers or topical/transdermal/injection preparations was small. We did not have sufficient power to investigate the odds of an error for topical, transdermal and injected preparations individually; additionally, the confidence limits associated with estimates for the administration in liquid form and by inhalers are wide.

It is important to consider the effect of MDS on other parts of the medicines management system-for example, the dispensing process. The prevalence of 
dispensing errors was threefold higher in the Care Homes' Use of Medicines Study compared with a similar study of dispensing errors in community pharmacies where MDS were excluded, ${ }^{12}$ although this higher proportion related mainly to one type of MDS. ${ }^{6}$ Errors when repackaging medicines into MDS for care-home residents have been found to be common in other countries. ${ }^{13} 14$ In addition, there is concern over the lack of stability data for medicines dispensed into MDS. ${ }^{7} 1516$

The repackaging of tablets and capsules involves pharmacy staff manually popping them out from the original packaging and placing them into MDS; this increases dispensing time ${ }^{8}$ and leads to significant costs associated with the equipment required. In addition, checking the accuracy of MDS is tedious and for some systems can be difficult because of the problem of identifying multiple tablets and capsules dispensed into a single compartment. However, MDS appear to reduce the time spent on the drug round. ${ }^{8} 9$

Despite a lack of robust evidence, MDS have been promoted as being safer systems than manufacturers' original packaging for administering medicines in care homes for older people. Although this study appears to suggest that administering medicines in MDS in care homes is safer (in the sense of being associated with fewer medication administration errors), the results should be interpreted cautiously for the reasons highlighted above. A study specifically designed to assess the impact of MDS is needed, ideally a randomised controlled trial, with sufficient power to definitively evaluate the effectiveness of MDS in this context. In addition, our study identified that medication administration errors occur frequently with medicines that cannot be packaged into MDS, such as liquids and inhalers, and there is a clear need for medication administration training for care home staff to address this. Future research should be conducted to develop and test educational interventions designed to improve the administration of non-oral dosage forms and complex devices in this setting.
Acknowledgements We thank the care home staff, residents, relatives, community pharmacists and general practitioners.

Funding The study was funded by the Patient Safety Research Programme of the Department of Health.

Competing interests None.

Ethics approval Ethics approval was provided by the Central Office for Research Ethics Committees.

Provenance and peer review Not commissioned; externally peer reviewed.

\section{REFERENCES}

1. Armour D, Cairns C, eds. Medicines in the Elderly. London: The Pharmaceutical Press, 2002.

2. Furniss L, Burns A, Craig SKL, et al. Effects of a pharmacist's medication review in nursing homes: randomised controlled trial. $\mathrm{Br} \mathrm{J}$ Psychiatry 2000;176:563-7.

3. Gurwitz JH, Field TS, Judge J, et al. The incidence of adverse drug events in two large academic long-term care facilities. Am J Med 2005;118:251-8.

4. Zermansky AG, Alldred DP, Petty DR, et al. Clinical medication review by a pharmacist of elderly people living in care homes-randomised controlled trial. Age Ageing 2006;35:586-91.

5. Alldred DP, Barber N, Buckle P, et al. Care home use of medicines study. Medication errors in nursing and residential care homes-prevalence, consequences, causes and solutions. Report to the Patient Safety Research Portfolio, 2009. http://www.haps.bham. ac.uk/publichealth/psrp/PS025_Project_Summary.shtml.

6. Barber ND, Alldred DP, Raynor DK, et al. Care homes' use of medicines study: prevalence, causes and potential harm of medication errors in care homes for older people. Qual Saf Health Care 2009;18:341-6.

7. Church C, Smith J. How stable are medicines moved from original packs into compliance aids? Pharm J 2006;276:75-81.

8. Rivers PH, Poston JW. Evaluation of a controlled medication system. Pharm J 1985;235:787-9.

9. Leinski PW, Thielke TS, Collings DM, et al. Cost comparison of unit dose and traditional drug distribution in a long-term-care facility. $A m \mathrm{~J}$ Hosp Pharm 1986;43:2771-9.

10. Allan EL, Barker KN. Fundamentals of medication error research. Am J Hosp Pharm 1990;47:555-71.

11. Dean B, Barber N. Validity and reliability of observational methods for studying medication administration errors. Am J Health System Pharm 2001;58:54-9.

12. Franklin BD, O'Grady K. Dispensing errors in community pharmacy: frequency, clinical significance and potential impact of authentication at the point of dispensing. Int J Pharm Pract 2007;15:273-81.

13. Carruthers A, Naughton K, Mallarkey G. Accuracy of packaging of close administration aids in regional aged care facilities in the Hunter area of New South Wales. Med J Aust 2008;188:280-2.

14. Gerber A, Kohaupt I, Lauterbach KW, et al. Quantification and classification of errors associated with hand-repackaging of medications in long-term care facilities in Germany. Am J Geriatr Pharmacother 2008;6:212-19.

15. Walker R. Stability of medical products in compliance devices. Pharm J 1992;248:174-5.

16. Donyai P. Quality of medicines stored together in multi-compartment compliance aids. J Clin Pharm Ther 2010;35:533-43. 
BMJ Quality

\& Safety

The influence of formulation and medicine delivery system on medication administration errors in care homes for older people

David Phillip Alldred, Claire Standage, Olivia Fletcher, Imogen Savage, James Carpenter, Nick Barber and David Kenneth Raynor

BMJ Qual Saf 2011 20: 397-401 originally published online February 7, 2011

doi: $10.1136 /$ bmjqs.2010.046318

Updated information and services can be found at:

http://qualitysafety.bmj.com/content/20/5/397

These include:

References This article cites 14 articles, 6 of which you can access for free at: http://qualitysafety.bmj.com/content/20/5/397\#BIBL

Email alerting Receive free email alerts when new articles cite this article. Sign up in the service box at the top right corner of the online article.

Topic Articles on similar topics can be found in the following collections Collections

Press releases (29)

\section{Notes}

To request permissions go to:

http://group.bmj.com/group/rights-licensing/permissions

To order reprints go to:

http://journals.bmj.com/cgi/reprintform

To subscribe to BMJ go to:

http://group.bmj.com/subscribe/ 